\title{
A MASTECTOMIA E SUAS REPERCUSSÕES NA VIDA AFETIVA, FAMILIAR E SOCIAL DA MULHER
}

\author{
THE MASTECTOMY AND ITS EFFECTS ON AFFECTIVE, \\ FAMILY AND SOCIAL LIFE OF WOMEN
}

\author{
Elisa da Luz Adorna', Elhane Glass Morari-Cassol², Nara Maria Severo Ferraz²
}

\section{RESUMO}

Objetivos: Identificar os problemas enfrentados pela mulher mastectomizada na vida afetiva, familiar e social. Metodologia: Realizou-se um estudo descritivo de caráter qualitativo, com 10 mulheres mastectomizadas, participantes do grupo de apoio Renascer. A coleta de dados deu-se por meio de entrevista, tendo como instrumento um questionário elaborado pela pesquisadora. Os dados foram posteriormente analisados de forma qualitativa conforme proposta de sistematização de Minayo. Resultados: Foram identificadas seis categorias. Neste artigo serão abordadas as categorias: vida afetiva, vida familiar e vida social. Conclusão: Identificou-se como problemas mais comuns no relacionamento da mulher mastectomizada, com familiares, companheiro e amigos, o afastamento das pessoas, a dificuldade de diálogo sobre o câncer de mama, e o preconceito. As mudanças positivas foram o fortalecimento dos laços familiares e de amizade e o apoio recebido pelas mulheres. As mulheres passaram a ser mais valorizadas e admiradas, pela família, companheiro e amigos.

Descritores: Neoplasias da Mama; Mastectomia; Saúde da Mulher.

\section{ABSTRACT}

Objectives: To identify the problems faced by mastectomy in life, emotional, social and family woman. Methodology: We conducted a descriptive qualitative study, with women mastectomies, participants support group Renascer. Data collection took place through interviews, with the instrument a questionnaire prepared by the researcher. The data were subsequently analyzed qualitatively as proposed to systematization of Minayo. Results: six categories were identified. In this paper the categories will be addressed: love life, family life and social life. Conclusion: It was identified as the most common relationship problems in women with mastectomies with family, partner and friends, withdrawal from people, the difficulty of dialogue on breast cancer, and prejudice. The positive changes were the strengthening of family ties and friendship and the support received by women. Women have become more valued and admired by family, partner and friends.

Descriptors: Breast Cancer; Mastectomy; Women's Health.
${ }^{1}$ Especialista Profissional em Fisioterapia Respiratória pelo Conselho Federal de Fisioterapia e Terapia Ocupacional.

${ }^{2}$ Doutora em Ciências da Saúde pela Universidade de Brasília (UnB), Brasília, DF, Brasil. 


\section{Introdução}

No Brasil o número de casos novos de câncer de mama esperado para o ano de 2016 é de 57.960, com um risco estimado de aproximadamente 56 ocorrências a cada 100 mil mulheres. Sem considerar os tumores de pele não melanoma, esse tipo de câncer é o mais frequente nas mulheres das regiões Sudeste, Sul, Centro-Oeste e Nordeste. Na região Norte é o segundo tumor mais incidente ${ }^{1,2}$.

O diagnóstico de qualquer tipo de câncer causa medo e apreensão, pois, muitas vezes, é visto como uma condenação à morte. $O$ tratamento do câncer de mama inclui cirurgia, quimioterapia, radioterapia e/ou hormonioterapia e pode causar sequelas físicas e psicológicas importantes que variam conforme o tipo de tratamento ${ }^{3}$.

A mama está relacionada à feminilidade, à sexualidade e à maternidade e, a mastectomia, pode afetar a identidade da mulher e repercutir na sua vida pessoal, afetiva, familiar e social, na autoestima e na imagem corporal.

É necessário que o fisioterapeuta, juntamente com os demais profissionais da saúde, identifique as repercussões do câncer de mama e do seu tratamento, especialmente em relação ao corpo e nas relações interpessoais da mulher, além das sequelas físicas, para compreender as necessidades e dificuldades da mulher mastectomizada. A interferência desses fatores poderá se manifestar não somente durante o tratamento ou imediatamente após este, mas também num período tardio, já que esta mulher poderá viver muitos anos e terá que readaptar-se para buscar melhor qualidade de vida.

Com base no exposto objetivou-se nesse estudo identificar as repercussões do câncer e seu tratamento na vida afetiva, na vida familiar, na vida social da mulher.

\section{Metodologia}

Realizou-se um estudo descritivo, de caráter prospectivo, com análise qualitativa dos dados.

Este estudo é parte da pesquisa intitulada "A mastectomia e suas repercussões na vida da mulher", aprovada pelo Comitê de Ética em Pesquisa (CEP) da Universidade Federal de Santa Maria sob o número CAAE 0163.0.243.000-09. Neste artigo serão apresentadas as análises referentes à vida afetiva, familiar e social.

O grupo de estudo foi constituído por dez mulheres submetidas à mastectomia por câncer de mama, participantes do Grupo de Apoio às Pacientes com Câncer de Mama do HUSM (Hospital Universitário de Santa Maria-RS) - grupo Renascer.

Como critérios de inclusão foram adotados: idade superior a 18 anos, realizado a cirurgia há no mínimo um ano e ser participante do grupo Renascer. Os critérios de exclusão foram: idade inferior a 18 anos, dificuldade de compreensão e estar em tratamento quimioterápico ou radioterápico.

Como instrumento de pesquisa utilizou-se um questionário elaborado pela pesquisadora com embasamento nos questionários EORTC QLQ-C30 (version 3) e EORTC QLQ-BR234. O questionário foi composto de duas partes, a primeira referente a informações gerais sobre a entrevistada, e a segunda com 36 questões estruturadas e abertas. Essas questões contemplaram alguns aspectos pessoais que poderiam influenciar a qualidade de vida da mulher com câncer de mama os quais foram utilizados como categorias para a apresentação e a análise dos resultados. 0 questionário foi submetido a um teste piloto com duas mulheres para verificar a sua aplicabilidade.

Inicialmente obteve-se acesso à lista nominal das 25 participantes do grupo e números de telefones de 15 dessas mulheres. Buscou-se o contato com todas as mulheres, obteve-se a resposta de 13 , três delas não preenchiam os critérios de inclusão e as outras dez aceitaram participar da pesquisa. A pesquisadora participou de algumas reuniões do Grupo Renascer para facilitar a aproximação com as mulheres.

As entrevistas foram realizadas pela pesquisadora, domiciliarmente, nos meses de fevereiro e março de 2010, com exceção de uma que foi realizada no ambulatório do HUSM, em uma sala reservada.

Após a concordância e assinatura do Termo de Consentimento Livre e Esclarecido, realizava-se a entrevista que foi gravada em áudio. Os dados foram posteriormente transcritos e analisados de forma qualitativa conforme proposta de sistematização de Minayo ${ }^{5}$, que consiste em ordenação de dados, classificação de dados e análise final. 


\section{Resultados e discussão}

Apresentam-se a seguir as características gerais das dez mulheres que participaram deste estudo. A faixa etária variou de 46 a 77 anos; cinco eram casadas, quatro viúvas e uma separada. Todas tinham filhos, variando de um a quatro. Quanto à escolaridade, três mulheres apresentavam ensino fundamental incompleto e três com ensino fundamental completo, três com ensino médio completo e uma com ensino superior completo.

Quatro eram donas de casa e seis trabalhavam fora de casa, sendo que uma era aposentada.

0 tempo de pós-operatório variou num intervalo entre um e 21 anos. Seis mulheres eram mastectomizadas à direita. Quatro haviam feito reconstrução mamária, sendo que dentre essas, três com retalho abdominal e uma com colocação de prótese de silicone. Nove mulheres necessitaram de tratamento adjuvante (quimioterapia, radioterapia e/ ou hormonioterapia) e apenas uma realizou somente a cirurgia. Oito entrevistadas foram submetidas à fisioterapia por um período de tempo variável e em diferentes épocas do pós-operatório.

Os resultados obtidos serão apresentados por categorias de análise e discutidos a seguir.

\section{Vida afetiva}

Nesta categoria destacam-se os relatos sobre o relacionamento com o companheiro.

A maioria das mulheres recebeu apoio do companheiro, este fato também foi observado por Talhaferro et al ${ }^{6}$; Kappaun e Ferreira ${ }^{7}$. Neste estudo também se encontrou uma situação na qual a entrevistada deu apoio ao companheiro. Apenas uma mulher disse ter se afastado do marido na época do tratamento. 0 parceiro pode ser fonte de suporte ou de estresse, dependendo da qualidade do relacionamento do casal ${ }^{8}$. A dificuldade de dar apoio à companheira e 0 afastamento do casal foram aspectos encontrados por Biffi e Mamede ${ }^{9}$ e relacionados pelos autores com a dificuldade de diálogo entre os casais.

E10 "Foi extremamente parceiro, até acho que sentiu mais a doença que eu...".

Apenas três mulheres disseram que seus companheiros ficaram nervosos ou apreensivos com o diagnóstico de câncer de mama.

E7 "Ele ficou assustado, quieto, mas depois que eu falei o que ia acontecer ele disse (não, eu vou contigo até a hora que terminar), ele foi muito companheiro".

Amaioria das entrevistadas disse que conversava com o companheiro a respeito do câncer na época do tratamento. Atualmente, a maioria disse não conversar mais sobre o assunto por considerarem uma fase superada ou por, talvez, não gostarem de falar no assunto com o companheiro.

A maioria das mulheres acredita que seus companheiros passaram a vê-las com admiração e a tratá-las com mais cuidado e atenção, como se observa nos relatos seguintes.

E5 "Ele acha que eu sou uma pessoa muito forte, porque qualquer outra pessoa sucumbiria, iria se entregar, se achar uma coitadinha, eu nunca fui coitadinha".

E6 "Com mais cuidado, mais atenção, porque ele me ajuda em tudo, serviço pesado que tiver que fazer ele faz, ele tá sempre me protegendo".

E7 “... parece que ele respeita mais, não como mulher, mas como ser humano...".

Huguet et a $/^{10}$, em uma pesquisa com 110 mulheres portadoras de câncer de mama, observaram que aquelas que possuíam uniões estáveis apresentavam melhores escores no domínio psíquico, relações sociais e sexualidade, o que corrobora a importância do companheiro na recuperação dessas mulheres.

De forma geral observou-se que após o câncer houve certos acréscimos positivos para o relacionamento dos casais. Segundo a literatura o momento da doença trás a oportunidade de reavaliar sentimentos e posturas dentro da relação conjugal e reencontrar a sua qualidade de vida desejada. 


\section{Vida familiar}

Neste aspecto foi observado o relacionamento das entrevistadas com seus familiares e, em especial, com seus filhos, os quais foram os mais citados nos relatos.

A maioria das mulheres disse que seus familiares ficaram nervosos e preocupados ao saberem do diagnóstico de câncer de mama, principalmente os filhos. Este aspecto também foi encontrado na pesquisa de Bervian e GirardonPerlini1 ${ }^{11}$ e pode ser observado nas seguintes falas:

E5 "Olha a minha familia ficou mais abalada do que eu...".

E9 "Minhas filhas ficaram nervosas, quer dizer ficaram transtornadas, abaladas".

E6 "... perto de mim nunca choraram, mas eles diziam que depois saiam de perto, cada um ia prum lado, choravam muito, ficaram muito abalados e eu não, e eu dando força pra eles...".

As mulheres tanto receberam apoio como apoiaram os filhos, inclusive uma delas relatou que a filha solicitou seu apoio:

E1 “... ela (a filha) falou (mãe eu quero ter um filho, quero ter minha mãe do lado, ter alguém que me ajude)...”.

A família precisa da mãe porque ela é um ponto de apoio da família, desempenha um papel de provedora e cuidadora, por isso a família, e os filhos principalmente, ficam com medo de perdê-la.

Apenas uma entrevistada disse ter se afastado das filhas após a cirurgia.

E9 "Eu até ficava mais isolada, mas elas respeitavam que eu queria ficar naquele canto, queria ficar mais sozinha".

Sete acreditam que passaram a serem vistas com admiração pela família.

A maioria das entrevistadas não falava com a família a respeito do câncer tanto na época do diagnóstico quanto atualmente, elas não queriam falar com a família a respeito do câncer ou a família não queria lembrá-las do assunto, tornando a doença um assunto proibido no núcleo familiar durante o tratamento, embora algumas mulheres falem sobre o assunto porque os filhos cobram que elas cuidem da saúde.

E5 "... eles procuravam não tocar no assunto pra não me lembrar. Agora normal, tranquilo, isso passou ninguém mais fala nisso...".

E10 “... falava assim (a radio é assim, a quimio é assim, eu tô assim) não é um falar, ficar cozinhando".

As mulheres demonstraram que receberam apoio da família e que houve maior aproximação e estreitamento nas relações familiares após o câncer de mama. Este aspecto também foi observado em outros estudos ${ }^{11,12}$, verificando-se a importância que o apoio familiar tem nas distintas fases após um diagnóstico de câncer de mama, já que a manutenção da estrutura de suporte emocional oferecida pela presença da família e dos amigos constitui um importante fator terapêutico, alicerçado no incentivo à aceitação e luta contra a doença ${ }^{13,14}$.

A doença é uma situação de crise na família, podendo contribuir ou dificultar as resoluções dos conflitos ${ }^{12}$. Diante desta situação a família procura elaborar estratégias para tentar reorganizar-se e/ou manter a estrutura familiar, fazendo com que esta permaneça unida ${ }^{11}$, por isso da necessidade de apoio também à família. 


\section{Vida social}

Observou-se a relação da mulher com seus amigos e atividades sociais.

A maioria das entrevistadas recebeu apoio dos amigos e pessoas próximas. Para Melo et a/ ${ }^{12}$ o apoio de amigos é importante como suporte emocional, ajudando no enfrentamento da doença, tanto para a mulher quanto para a sua família.

E2 “... saia cinco e entrava dez pra me visitar, naqueles dias, eu tive visita que não deu tempo nem de pensar muito... é a melhor coisa que a gente tem."

As mulheres disseram que passaram a ser tratadas com mais atenção por parte dos amigos e pessoas conhecidas e acreditam que os amigos passaram a vê-las de maneira mais positiva (com admiração, como exemplo de vida ou uma pessoa forte).

E10 "... talvez no sentido de eu ser mais penalizada, mais cuidada, mais tentando colocar (tu tem que se cuidar), nessa linha aí".

E5 "Eles me veem como exemplo de vida, e eu sempre passo pra eles que tem que ser forte, muitos outros já tiveram... então eles veem falar comigo....".

Em alguns momentos foi observado que as entrevistadas distinguiam os amigos dos amigos "verdadeiros", sendo que esses realmente deram apoio a elas. Talhaferro et al também verificaram esta distinção em seu estudo.

Uma delas disse que não falava muito sobre o assunto por causa de "pessoas negativas", esse fato foi citado por mais três mulheres como motivo para terem escolhido para quem contar sobre o câncer ou o que contar a cada pessoa.

E1 "Eu não falava muito porque tem pessoas que ficam achando que vai morrer, deu aqui já vai dar em outro lugar...".

E10 “... eu não queria pena, eu não queria que ficassem (ai coitadinha, pobrezinha, não merecia ou merecia)...".

Todas as mulheres disseram ter retornado às suas atividades sociais, como festas, jantares e bailes. Acredita-se que este fato possa estar relacionado ao apoio e estímulo recebido tanto dos familiares quanto dos amigos. Em estudo realizado por Pinto e Gióia-Martins ${ }^{15}$, a maioria das mulheres acompanhadas também retornou com facilidade às suas atividades sociais de costume. Duarte e Andrade ${ }^{16}$ não observaram o mesmo, e dizem que é a partir da retomada dos relacionamentos sociais, atividades de lazer, trabalho e família que surgem as preocupações relacionadas ao próprio corpo, ao defrontar-se com a realidade, as mulheres passam a reavaliar e reelaborar suas potencialidades e as formas diferenciadas de relacionar-se com o próprio corpo e com os outros.

\section{Considerações Finais}

O câncer de mama e o seu tratamento são momentos difíceis na vida da mulher, familiares e também amigos.

Neste estudo identificaram-se como problemas mais comuns no relacionamento da mulher mastectomizada com familiares, companheiro e amigos, o afastamento das pessoas, a dificuldade de diálogo sobre o câncer de mama, durante ou após o tratamento, e o preconceito ou medo deste.

As mudanças positivas nos relacionamentos que foram observadas neste estudo foram o fortalecimento dos laços familiares e de amizade e o apoio recebido pelas mulheres. Passaram a ser mais valorizadas e admiradas, pela família, companheiro e amigos.

Este estudo tem como relevância apresentar aos profissionais de fisioterapia e de outras áreas da saúde algumas situações e dificuldades vivenciadas pela mulher mastectomizada para que possam ser consideradas, como auxílio à recuperação física e emocional da mulher. 


\section{Referências}

1. Instituto Nacional de Câncer José Alencar Gomes da Silva. http://www2.inca.gov.br/wps/wcm/connect/inca/portal/ home. Acesso em 31/01/2016.

2. Fundação do câncer. http://cancer.org.br/. Acesso em 17/01/2016

3. Correia GN, Oliveira J; Mesquita-Ferrari RA. Avaliação da qualidade de vida em mulheres submetidas à mastectomia radical e segmentar. Fisioterapia e Pesquisa; 2007; 14(3): 31-36.

4. European Organization for Research and Treatment of Cancer. http://groups.eortc.be/qol/questionnaires_modules.htm. Acesso em 21/06/2009.

5. Minayo MCS. O desafio do conhecimento-Pesquisa qualitativa em saúde. São Paulo-Rio de Janeiro: Hucitec-Abrasco; 1992. 6. Talhaferro B, Lemos SS, Oliveira E. Mastectomia e suas conseqüências na vida da mulher. Arq Ciênc Saúde; 2007; 14(1): 17-22.

7. Kappaun NRC, Ferreira MEC. A imagem corporal de mulheres mastectomizadas. HU Revista; 2008; 34(4): $243-248$.

8. Conde DM, Pinto-Neto AM, Júnior RF, Aldrighi JM. Qualidade de vida de mulheres com câncer de mama. Rev Bras Ginecol Obstet; 2006; 28(3): 195-204.

9. Biffi RG, Mamede MV. Suporte social na reabilitação da mulher mastectomizada: o papel do parceiro sexual. Rev Esc Enferm. 2004; 38(3): 262-269.

10. Huguet PR, Morais SS, Osis MJD, Pinto-Neto AM, Gurgel MSC. Qualidade de vida e sexualidade de mulheres tratadas de câncer de mama. Rev Bras Ginecol Obstet; 2009; 31(2): 61-67.

11. Bervian PI, Girardon-Perlini NMO. A família (con)vivendo com a mulher/mãe após a mastectomia. Rev Bras Cancerol: 2006: 52(2): 121-128.

12. Melo EM, Silva RM, Fernandes AFC. O relacionamento familiar após a mastectomia: um enfoque no modo de interdependência de Roy. Rev Bras Cancerol; 2005; 51(3): 219-225.

13. Stumm EMF, Maçalai C, Leite MT, Loro MM. Mecanismos de coping utilizados por mulheres mastectomizadas para lidar com o estresse. Scientia Medica; 2009; 19(3); 108-114.

14. Andrade GN, Panza AR, Vargens OMC. As redes de apoio no enfrentamento do câncer de mama: uma abordagem compreensiva. Cienc Cuid Saude; 2011; Jan/Mar; 10(1): 82-88.

15. Pinto AC, Gióia-Martins DF. Qualidade de vida subseqüente à mastectomia: subsídios para intervenção psicológica. Universidade Presbiteriana Mackenzie; [s.d.].

16. Duarte TP, Andrade NA. Enfrentando a mastectomia: análise dos relatos de mulheres mastectomizadas sobre questões ligadas à sexualidade. Estudos e Psicologia; 2003; 8(1): 155-163.

\section{Elisa da Luz Adorna}

Endereço para correspondência - Rua: Guilherme Alves, n 469, Ap 216, Bairro: Partenon, CEP: 90690-001, Porto Alegre, RS, Brasil.

E-mail: elisa_adorna@hotmail.com

Lattes: http://lattes.cnpq.br/-

Elhane Glass Morari-Cassol - elhanegmc@gmail.com

Nara Maria Severo Ferraz - nsferraz@gmail.com

Enviado em 01 de agosto de 2016. Aceito em 17 de outubro de 2016. 